\title{
Modelling online community constructs through interaction data: A learning analytics based Approach
}

\author{
Ünal ÇAKIROĞLU' ${ }^{1}$. Sefa KAHYAR ${ }^{1}$
}

Received: 29 November 2021 / Accepted: 9 February 2022 / Published online: 4 March 2022

(c) The Author(s), under exclusive licence to Springer Science+Business Media, LLC, part of Springer Nature 2022

\begin{abstract}
This study aims to use LMS log data to suggest a way to understand CoI constructs. Students' interactions in Moodle components were weighted for indicators of cognitive, teaching and social presences. Traces reflecting students' online interactions were obtained from the Moodle LMS and analyzed through learning analytics techniques. The data is examined with the Euclidean Distance Model, and Correspondence Analysis methods to evaluate the levels of interactions and presences. The results indicated that, cognitive presence is at the center of the CoI constructs, and student-content interaction, is found is more prominent than other interactions in terms of its relation to cognitive presence. Social presence scores were mostly related with student-student and student-teacher interaction scores. In addition, teaching presence scores were found in parallel with student-system interaction scores.
\end{abstract}

Keywords Community of inquiry - Learning analytics - Correspondence analysis · Online interactions

\section{Introduction}

Considerable effort has been invested in the Community of Inquiry (CoI) model to provide much empirical evidence about social, cognitive and teaching presences and enhance student learning experience. At this point, student-student, student-teacher and student-content interactions have an important place in the CoI model (Garrison et al., 1999). The CoI is one of the well-tested pedagogical frameworks that have been

Ünal ÇAKIROĞLU

cakiroglu@ktu.edu.tr

1 Department of Computer Education and Instructional Technology, Fatih Faculty of Education, Trabzon University, 61335Söğütlü, Akçaabat, Trabzon, Turkey 
commonly contributed to online learning studies and applications. Many researchers used this model to determine the extent of the interactions identifying and evaluating the quality of the cognitive, teaching and social presences in an online environment (Akyol \& Garrison, 2008; Arbaugh et al., 2008; Castellanos-Reyes, 2020; Garrison et al., 2010; Jansson et al., 2021; Kovanović et al., 2015).

Over the years, various methods were used to study the constructs in particular, or some useful instruments were used to measure the CoI constructs separately (Anderson et al., 2001; Arbaugh \& Hwang, 2006; Arbaugh et al., 2008; Jansson et al., 2021; Kovanović et al., 2019; Shea \& Bidjerano, 2009; Shea et al., 2003; Wertz, 2022). Depending on learning settings, instructor roles and the teaching approaches, the tools for measuring the three presences, were varied. For instance, in the years when this model was first started to be used, some researchers emphasized the limitations of self-report survey measures that they can be insensitive to change over time (Kramer et al., 2006; Lowenthal \& Dunlap, 2014). Some others also addressed that using multiple tools or various quantitative or qualitative data collection approaches can provide more reliable results about interactions in online learning (Lowenthal \& Leech, 2010). For instance, Lowenthal (2012) suggested analyzing some modified versions of the indicators developed by Garrison and his colleagues. In the following years, CoI studies were carried out sometimes through surveys (Alaulamie, 2014; Garrison et al., 2010; Maddrell et al., 2011), sometimes only via discussion records (Shea et al., 2010; Wanstreet \& Stein, 2011) and in a few studies via both surveys and discussion records (Akyol \& Garrison, 2011; Akyol et al., 2009). At this point, Çakıroğlu and Kılıç (2018) assessed students' behaviors and perceptions in terms of online presences and confirmed that learners' behaviors and perceptions are quite similar. On the other hand, researchers also used social network analysis (SNA) to explore communities in online learning. For instance, Jan and Vlachopoulos (2019) presented the Integrated Methodological Framework which uses SNA to identify communities in higher education online learning (HEOL).

While some research is already working on it, currently a need exists for more research in order to better determine the CoI presences in online settings. Though it is somewhat easy to gather perceptional data via self-reporting techniques, it is difficult to track behavioral data in online learning which is in the scope of learning analytics. The learning analytics techniques provide useful information from the data regarding the learners' actions which are captured, tracked and logged (Vivakaran \& Maraimalai, 2018). Analyzing data via learning analytics can provide accurate predictions about some variables regarding the learning process. Thus, in this study an approach to measure learners' social, cognitive and teaching presences regarding their behaviors in online learning is proposed. In this way, valuable insights for instructors or instructional designers to predict learning outcomes or to manage the learning process such as giving meaningful feedback for the online learners might be provided.

In the definition of the CoI, the social, cognitive and teaching presences are explained by interactions. Thus, A structural link between online interactions and the $\mathrm{CoI}$ frameworkis established considering the nature of $\mathrm{CoI}$ constructs. 


\subsection{Theoretical Framework}

Constructing knowledge and creating a community is essential in online learning and interaction is considered as one of the key factors creating a quality community. Because successful online courses create a CoI where students interact with one another, the instructor and the learning materials and develop new knowledge and skills (Rubin et al., 2013). When learners feel a higher degree of interaction in online settings, generally a strong $\mathrm{CoI}$ is constructed so that students can mostly participate in discussions, have a learning experience and higher perceived learning outcomes (Boston et al., 2009; Eom et al., 2006; Garrison \& Cleveland-Innes, 2005; So \& Brush, 2008). Thus, considering the level of interactions among learners, teachers and content; instructional designers can create appropriate learning settings (AgudoPeregrina et al., 2014; Beldarrain, 2006).

In online learning, student-student interaction is the exchange of knowledge among learners (Arbaugh \& Benbunan-Fich, 2007). Student-teacher interactions are related to the level of involvement of the instructor with the students (Agudo-Peregrina et al., 2014; Nieuwoudt, 2018). Student-content interactions occur when students work with digital documents, assessments, videos, audio materials, e-books or other learning materials (Bernard et al., 2009). Additionally, Hillman, Willis and Gunawardena (1994) proposed a student-system interaction, reflecting students' use of the system with the interface. Such interactions are investigated in the CoI framework which is an effective way to explain success in online teaching and learning (Garrison et al., 2001; Garrison et al., 2010).

\subsection{Community of Inquiry (Col)}

The CoI is a useful framework in guiding research and practice in online higher education (Garrison \& Arbaugh, 2007) and it is empirically proven to be effective in explaining individual and collective learning (Shea \& Bidjerano 2010). Stenbom

Fig. 1 Community of Inquiry framework (Garrison \& Arbaugh, 2007)

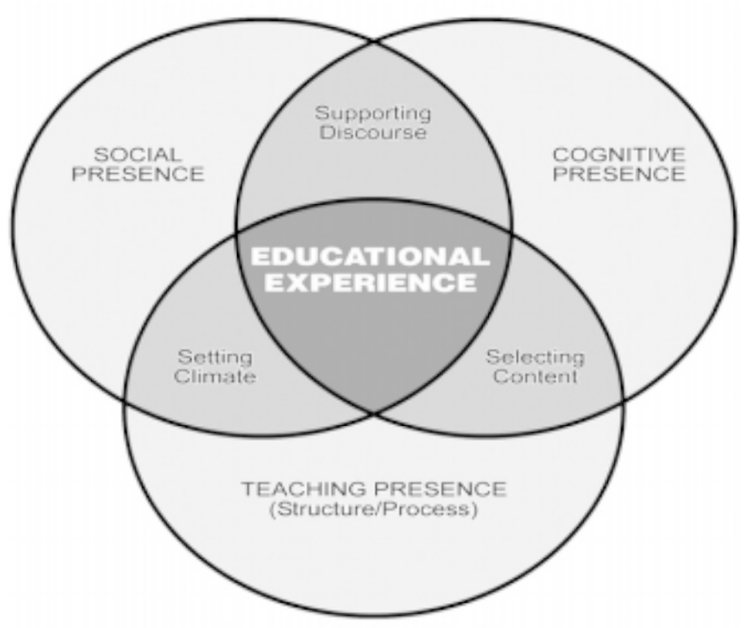


(2018) argued that the CoI framework takes its roots from the collaborative constructivism that considers online courses successful when students engage in a community for knowledge construction. The model is grounded in critical thinking, collaborative learning and practical inquiry to understand the dynamics of online learning experiences. The CoI model (shown in Fig. 1) focuses on the instructor and students together forming an online learning community consisting of social, cognitive and teaching presences.

Cognitive presence focuses on students' development of critical and higher-order thinking. Constructing knowledge through interactions is considered in cognitive presence (Garrison, Anderson, \& Archer, 1999). Social presence refers to the development of social interactions among the learning group within a productive social climate. It is about learners and instructors' feeling of real people with social communication (Garrison \& Arbaugh, 2007). Teaching presence occurs when instructors design, support and direct student activities to provide a meaningful learning experience (Rubin et al., 2013). Teaching presence involves designing materials, implementing learning activities and facilitating discussions in the teaching process (Garrison, Anderson, \& Archer, 1999). Although Shea and Bidjerano (2010) proposed learning presence (LP) which emerged from a constellation of motivational and behavioral traits that drive self-regulation as a fourth inter-related construct, few studies have addressed this construct (Shea \& Bidjerano, 2012 ; Wertz, 2022).

Many studies take $\mathrm{CoI}$ as a framework and try to understand the learning process in LMSs to provide presentations, discussions, reflections and communications (Akyol \& Garrison, 2011; Kozan \& Richardson, 2014; Morueta et al., 2016; Tirado et al., 2015; Wicks et al., 2015). It is critical to determine the three presences in LMSs because the relationships among students and teachers give hints about the quality of the instructional process.

\subsection{Determining Presences in Community of Inquiry}

To determine the realization level of the three presences, some researchers suggest considering students' discussion messages and applying content analysis by using pre-defined coding schemes (Garrison et al., 2001; Jansson et al., 2021; Kovanović et al., 2015; Stein et al., 2007). In addition, self-reported instruments such as scales are also used to measure students' perceived levels of the presences regarding the corresponding items in the $\mathrm{CoI}$ framework. At this point, one popular CoI survey instrument was developed by Arbaugh et al. (2008). Adapted to various languages, it was used in various kinds of online settings to provide statistical insights into the presences. However, the data obtained through the scale reveal student's perceptions of cognitive, social and teaching presences as much as participants' responses.

CoI model suggests a coding scheme that describes each phase of the constructs with a set of indicators of particular theorized socio-cognitive processes. In fact, the coding scheme has been proven to be sufficient levels of inter-rater reliability to be considered as a valid construct (Kovanović et al., 2016; Hind et al., 2018). However, the use of this type of instrument is time-consuming and needs the intervention of experienced coders since it requires manual analysis of textual data (Darabi et al., 2011; Mills, 2016). 
On the other hand, researchers are concerned not just with how people perceive each of the three presences, but also with what people actually do during online courses. This may be revealed through monitoring the interactions. Without any doubt, interactions in online learning environments do not completely signify learning; however, interactions reflect the potentials to learn in the environment by allowing knowledge-creation. Considering the linkage between structural components of the $\mathrm{CoI}$ and the nature of the interaction data, this paper, proposes that how learners interact with the components of online learning in the community can be revealed through analyzing the interaction data. For instance, if someone provides likes, comments, shares in the community, some conclusions can be made about the social, cognitive and teaching presences. Hence, this can support the measurement systems in terms of CoI.

\subsection{Applying Learning Analytics to Get Data for Col Constructs}

Learning analytics (LA) is a fast-growing area in online learning research. LA focuses on optimizing opportunities for online learning (Ferguson, 2012). The Society for Learning Analytics Research defines learning analytics as: “... the measurement, collection, analysis and reporting of data about learners and their contexts, for the purposes of understanding and optimizing learning and the environments in which it occurs." LA aims to improve the instructional process by providing instructors to be aware of learners' behaviors to take necessary measures for efficient learning (Hind et al., 2018; Siemens \& Baker, 2012). In addition, LA aims to support performance prediction to improve learning outcomes (Agudo-Peregrina et al., 2014; Xing et al., 2015).

Although it has been accepted that interactions are valuable predictors of success in online learning environments (Akyol \& Garrison, 2008), it is difficult to define which type of interactions are more effective in certain teaching situations. One of the main reasons for this difficulty is the lack of accurate measurements for interactions in online environments. In this context, the use of LA through online interactions can contribute with powerful measurements to the CoI studies. To do so, more objective measurements can be realized by considering the level of cognitive, teaching and social presences depending on the interaction behavior data in the online learning environment. To provide accurate measurements, online interactions and CoI components should be properly associated. When this relationship is established, CoI components can be predicted by taking the online traces into account, and predictions regarding learning outcomes can be made. It can be posit that the communities of inquiry can be studied with the indicators of each presence in online learning environments.

\subsection{Aim of the Study}

The review in existing research showed that, to date research which has considered how interaction data reflect the development of CoI constructs is limited. Using measurements related to interaction data via logs, more objective results can be offered for the CoI constructs. If the question of "Does LMS log data say something about 
the level of presences in CoI?" is answered, some suggestions can be made for future research so that meaningful learning can occur through student logs in LMSs. In this study, students' online interactions were obtained directly from tracks in the Moodle LMS and analyzed through learning analytics techniques. More specifically, our research addressed the following question: To what extent do the online interaction data indicate the development of the $\mathrm{CoI}$ constructs in online learning?

\section{Method}

The current study was carried out as a relational study which provided an opportunity to collect data in order to determine whether, and to what degree, a relationship existed between two or more quantifiable variables. The purpose of this relational study is to determine relationships between interactions and the $\mathrm{CoI}$ indicators exhibited in online environments to make predictions. In addition, the current study shows the application of data analysis techniques, correspondence analysis and multidimensional scaling analysis to verify results. Multidimensional scaling (MDS) aims to find proximity data (similarities or dissimilarities) as distances (usually Euclidean) among points in a multidimensional space (Anowar et al., 2021; Borg et al., 2012; Cox \& Cox, 2008). MDS analysis was employed to determine the relationship between the social, cognitive, teaching presences of participants and student-student, student-teacher, student-content, student system interactions in the LMS. Correspondence analysis, on the other hand, is an explanatory multivariate analysis technique that was employed to reveal the relationship between the levels of interactions and levels of presences. The method is especially helpful in analyzing cross-tabular data which is in the form of numerical frequencies. Additionally it results in a graphical display that allows more rapid interpretation and comprehension of the data (Greenacre, 2007).

\subsection{Participants}

Using the convenience sampling method, a sample of 49 (12 female, 37 male) vocational school students were recruited to participate in the study. Convenience sampling is a type of nonrandom sampling where the participants that meet certain practical criteria, such as easy accessibility, geographical proximity, cost-effectiveness, availability at a given time, or the willingness to participate are included for the purpose of the study (Creswell \& Poth, 2016; Etikan et al., 2016; Given, 2008; Rahi, 2017). The participants were 2nd-grade Computer Programming students who enrolled in the Web Programming course at a state university in Turkey and had basic knowledge about web design. Although students had no previous experiences with using Moodle LMS, they had sufficient knowledge and skills to use the system.

\subsection{Process}

During 14 week, students followed the lessons weekly via Moodle LMS. They were allowed to interact with the various Moodle components such as SCORM package, 
Forum, Assignment, Dictionary, Quiz and Chat on the weekly units. The activities in the units were given in 15 headings such as "Introduction to Web Programming", "Variables and Objects", "Functions", "Regular Expressions", "Forms" and "Introduction to Database with PHP". Moodle media components used for the purposes are specified in Table 1.

The instructor who prepared and presented the content to the students acted as a guide during the process and directed the students in the discussions. He encouraged students to be active in the process by opening discussion topics related to the relevant unit. The interactions of the students with the system and the content were supported by the quizzes prepared by the instructor.

\subsection{Data Collection Tools}

Since the study was conducted as a relational study, the variables were of two different sources.

Moodle System Logs Moodle log records were used to analyze the students' traces with learning analytics. The data such as the frequencies of use of the forum, message, quiz, scorm, survey, assignment and dictionary were obtained and visualized by Moodle plugins.

The CoI instrument The Turkish version of the CoI questionnaire was used to assess students' perceptions about the three presences in their online learning experiences. It was developed by Arbaugh et al. (2008) and adapted into Turkish and validated by Öztürk (2012). The instrument consisted of 34 items, having a 5-point Likert type scale ranging from 1-Strongly Disagree to 5-Strongly Agree. The number of items comprising each factor is 13 (for teaching presence), 12 (for cognitive presence) and 9 (for social presence).

Expert Evaluation Form While Moodle system logs are associated with students' interactions on the system, each type of interaction should be matched with the com-

Table 1 Moodle components and their purposes of use

\begin{tabular}{|c|c|}
\hline Moodle Components & Purpose of Use \\
\hline Scorm & $\begin{array}{l}\text { Textual, visual and audio presenta- } \\
\text { tion of the course contents }\end{array}$ \\
\hline Forum & $\begin{array}{l}\text { Sharing, monitoring and answering } \\
\text { various questions and interesting in- } \\
\text { formation by the lecturer or students }\end{array}$ \\
\hline Chat & $\begin{array}{l}\text { Communicating with both instruc- } \\
\text { tors and peers }\end{array}$ \\
\hline Assignment & $\begin{array}{l}\text { Receiving assignments given within } \\
\text { the scope of the subjects }\end{array}$ \\
\hline Quiz & $\begin{array}{l}\text { Unit-based exams excluding mid- } \\
\text { term and final exams }\end{array}$ \\
\hline Dictionary & $\begin{array}{l}\text { Summarizing the new concepts and } \\
\text { codes learned in each subject }\end{array}$ \\
\hline
\end{tabular}


ponents provided by Moodle LMS. This operation was performed through expert opinions. This form was designed by the researchers including Moodle components (survey, forum, scorm, quiz, chat, dictionary) and events in the components (message display/message sending, etc.). The average values of experts' evaluations were taken into consideration to reveal the weight of the Moodle components to the interactions. The experts are instructors who design and present sources in the online learning field for many years. The use of data collection tools is summarized as in Fig. 2.

\subsection{Data Analysis}

Data analysis included analyzing log data and comparing them with the data from the CoI scale. In the first stage, Moodle system logs were examined. Quantitative data, that is, students' number of the chat messages, forums they viewed, the discussions they were involved in, the number of the exams and assignments they completed, the number of the attendance of the questionnaires, and the frequencies of watching course videos, were obtained from the logs. Multidimensional scaling analysis was used to determine the relationship between the social, cognitive, teaching presences of participants and student-student, student-teacher, student-content, student-system interactions in the online learning environment. To reveal the relationship between interactions (student-student, student-teacher, student-content and student-system) and presences (social, cognitive and teaching), students were divided into groups according to their interaction and presence scores (low and high). The relationship between these groups was examined with the correspondence analysis. Correspondence analysis is an explanatory multivariate analysis technique that allows the categories of each variable to examine their relationships through maps (Clausen, 1998).

\subsection{Interaction-Events Model}

Although the linkage between presences and interaction is obvious in the theoretical definitions of educational experience in CoI, an examination is needed to define which events in the LMSs correspond to which interactions. There is a need for a model to transform the obtained data into a structure that can be used with learning analytics techniques by cleaning and reducing them. Although it is possible to create different models for this transformation, a way that is based on expert opinions is followed in this study. Since the model is about matching the interactions with the events in Moodle, the model is called as "Interaction-Events Model". In this way, the values of interactions (student-student, student-teacher, student-content and studentsystem) were determined quantitatively depending on the expert opinions. The way to determine the interaction scores in each module is presented in Fig. 3.

Fig. 2 Use of data collection tools

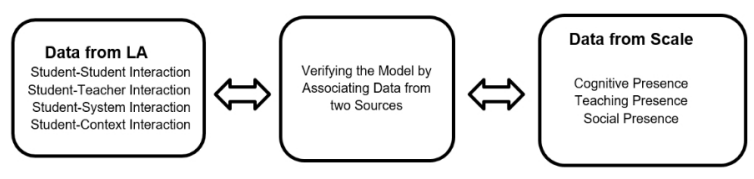


Fig. 3 Calculation of interaction scores with $\log$ data

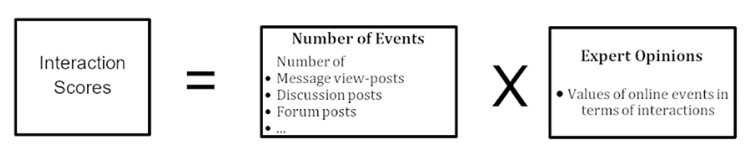

As shown in Fig. 3, the scores of the interactions for three types were obtained by multiplying the log data obtained with the LA and the coefficients obtained from the expert opinion form.

For instance, one students' student-student interaction score is calculated as:

Student-Student $\quad(\text { Score })_{i}=$ weight_of_survey*f_survey_post ${ }_{i}+$ weight_of_assignment*f_assignment_post ${ }_{i}+$ weight_of_forum*f_forum_post $t_{i}+$ weight_of_scorm*f_scorm_view + +weight_of_quiz*f_quiz_post +weight_of_system*f_quiz_system + weight_of_chat*f_quiz_chat ${ }_{i}+$ weight_of_dictionary*f_quiz_dictionary ${ }_{i}+. .$.

\section{Results}

In this section, the relationships between student-student, student-teacher, studentcontent, student-system interactions and the level of social, cognitive, teaching presences are presented. In this study, expert opinions were evaluated to reveal the interactions included in the Moodle components. In this context, the activities carried out in the main components of Moodle LMS were considered to reflect the interactions within the framework of the values as presented in Table 2.

Table 2 shows the average values for Moodle components obtained through the Expert Opinion Form. According to expert opinions, assignment component is mostly related with student-teacher and student-content interactions. Student-student interaction comes front in forum component and the experts stated that student-teacher interaction is crucial for forum component. On the other hand, scorm component mostly reflects student-content and studentsystem interactions. Student-content and student-system interactions are also valuable for exam component. While the system components include student-system and student-content interactions, chat components reflect student-student and student-teacher interactions to a large extent. Considering Table 2, the interaction scores of all of the students were calculated. For example: the student-student interaction score of the S1 is as follows: Student Student (Score) $1=1,25 * 39,651+2,5 * 47,0229+52,5 * 57,2301+5 * 46,0778+5 *$ $43,8095+5^{*} 70,8398+26,25^{*} 51,7485+2,5^{*} 43,6205=5442,79$ Table 3 presents the average values of the Moodle components forming interaction scores.

Table 2 Average values about the events in Moodle regarding expert opinions

\begin{tabular}{lccrrrrrrr}
\hline & Survey & Assignment & Forum & SCORM & Quiz & System & Chat & Dictionary & Total \\
\hline Student-Student & 1,25 & 2,5 & 52,5 & 5 & 5 & 5 & 26,25 & 2,5 & $100 \%$ \\
Student-Teacher & 3,75 & 20 & 25 & 5 & 7,5 & 13,75 & 22,5 & 2,5 & $100 \%$ \\
Student-Content & 2,5 & 13,75 & 13,75 & 27,5 & 12,5 & 15 & 6,25 & 8,75 & $100 \%$ \\
Student-System & 5 & 7,5 & 8,75 & 7,5 & 11,25 & 48,75 & 7,5 & 3,75 & $100 \%$ \\
\hline
\end{tabular}


Table 3 Average values of the components constituting interaction scores

\begin{tabular}{lccrccccc}
\hline & Survey & Assignment & Forum & SCORM & Quiz & System & Chat & Dictionary \\
\hline $\begin{array}{l}\text { Student- } \\
\text { Student }\end{array}$ & 53,9 & 114,5 & 3180 & 238,3 & 225,1 & 345,4 & 1188,8 & 108,7 \\
$\begin{array}{l}\text { Student- } \\
\text { Teacher }\end{array}$ & 161,6 & 915,9 & 1514,2 & 238,3 & 337,6 & 949,9 & 1019 & 108,7 \\
$\begin{array}{l}\text { Student- } \\
\text { Content }\end{array}$ & 107,7 & 629,7 & 832,9 & 1310,8 & 562,7 & 1036,2 & 283,1 & 380,6 \\
$\begin{array}{l}\text { Student- } \\
\text { System }\end{array}$ & 215,4 & 343,5 & 530 & 357,5 & 506,4 & 3367,8 & 339,7 & 163,1 \\
\hline
\end{tabular}

\subsection{Relationship between Interactions and Perceived Col Components}

Students' Perception of CoI Components.

The responses of the students to the CoI scale and the log data which were obtained from the LMS were compared to determine how the log data reflect perception data. Table 4 shows the average scores from the CoI scale regarding the presences.

The CoI scale scores indicate that the scores of teaching presence (3.02) were higher than social (2.60) and cognitive presences (2.78).

\subsection{Relationship between the Scores from Scale and the Log Data}

The positions of the social, cognitive and teaching presences of the participants which were obtained by the CoI scale, and student-student, student-teacher, studentcontent and student-system interaction levels of the participants in the online learning environment are shown in the two-dimensional graphic for Euclidean distance model

Table 4 Scores from CoI Scale

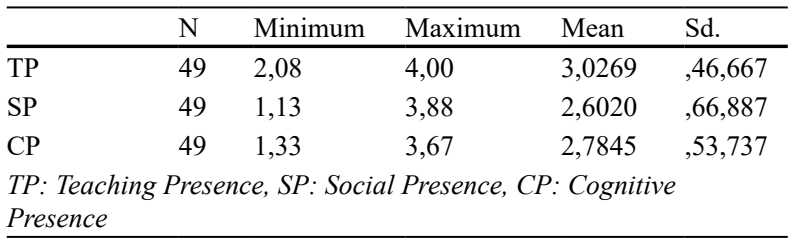

Fig. 4 Euclidean distance model

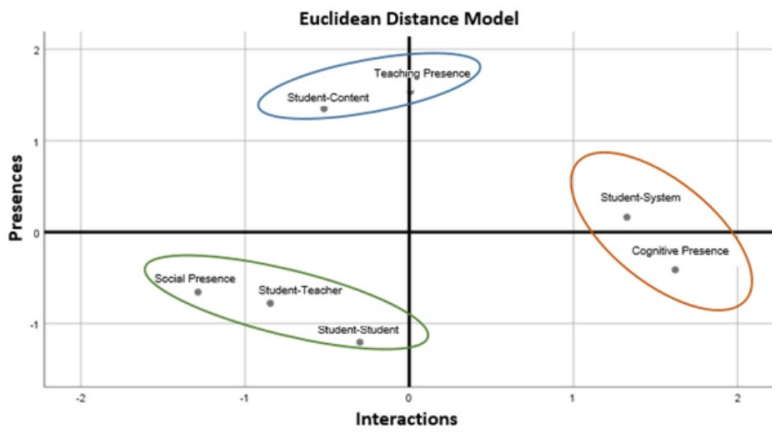


of multidimensional scaling analysis (Fig. 4). Based on the positions in this graph, it will be possible to develop an idea about whether CoI components can be evaluated.

According to Fig. 4, student-student and student-teacher interactions were grouped with social presence. However, it was found that while student-content interaction was related to teaching presence, student-system interaction was related to cognitive presence. Kruskal Stress value was obtained as shown in Table 5.

The result of the test $(\mathrm{RSQ}=, 73,663)$ shows that the stress value is approximately $74 \%$ explanatory.

The students were separated into groups according to their interaction scores and presence scores (high or low) to reveal in-depth the relationship between student-student, student-teacher, student-content, student-system interactions and social, cognitive, teaching presences. The groups were formed based on the average presence and interaction scores of all students. In these groups, the relationship between the scores of the students with low and high interaction scores and the scores of the students with low and high scores was determined by applying correspondence analysis. The visual results obtained from the analysis are presented in Fig. 5. Although the data were examined in-depth with the Euclidean Distance Model, it was possible to evaluate the same data with the Correspondence Analysis method to evaluate the results of the analysis over the grouped data, to make evaluations over the levels of interactions and presences, and, thus, making interpretations that take into account the limitations created by the sample number. The results of correspondence analysis are shown in Fig. 5.

Figure 5 illustrates the relationships between levels of interactions and levels of presences. The proximity of each expression shown on the graph demonstrates their relationship. It is indicated that the interaction types of the students were evaluated

Table 5 Kruskal stress value

Fig. 5 The relationship between students' interaction scores and presence scores (graph of correspondence analysis)
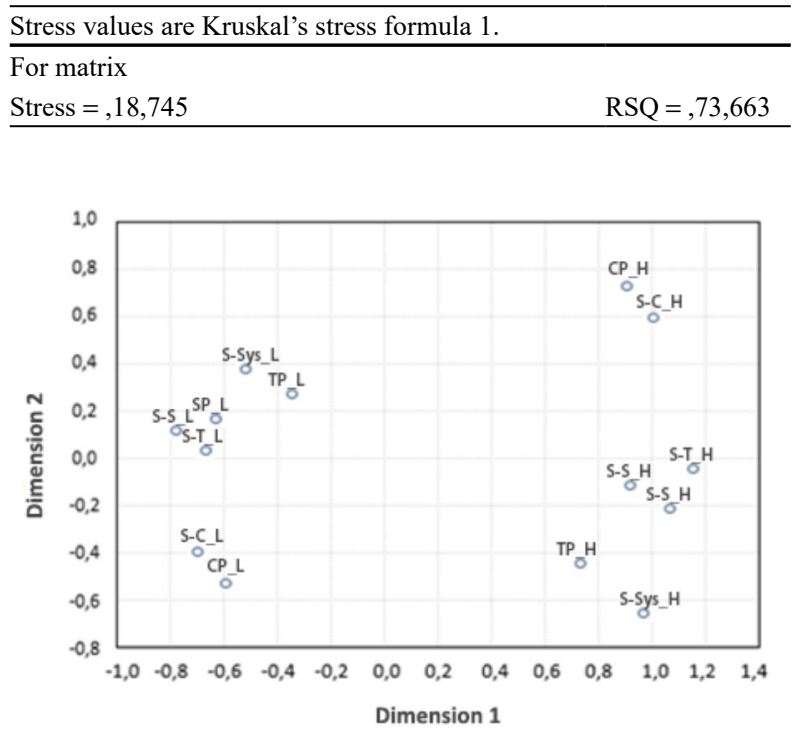
in three categories (i. student- content, ii. student-system, iii. student-student and student-teacher) and the presences were evaluated in three categories (i. social presence, ii. cognitive presence, iii. teaching presence). According to this relation, Fig. 5 indicates that the students with high cognitive presence scores $\left(\mathrm{CP}_{-} \mathrm{H}\right)$ have higher student-content interaction scores $\left(\mathrm{S}-\mathrm{C} \_\mathrm{H}\right)$ and students with low cognitive presence scores (CP_L) have low student-content interactions (S-C_L).

Similarly, the students with high teaching presence $\left(\mathrm{TP}_{-}^{-}{ }_{-}\right)$scores have high student-system interaction (S-Sys_H) scores and the students with low teaching presence scores (TP_L) have low student-system interaction scores (S-Sys_L). However, it is understood that when the students have high social presence scores $\left(\mathrm{SP}_{-} \mathrm{H}\right)$, their student-student (S-S_H) and student-teacher (S-T_H) interaction scores are also high. On the other hand, the students with low social presence scores (SP_L) have low student-student (S-S_L) and student-teacher interaction scores (S-T_L $)$ and it seems that they form a group. In addition, when the positions of the presences interrelated with the interaction types are considered, it is seen that the social and teaching presences are differentiated from the cognitive presence.

\section{Discussion}

In this study, the log data reflecting the interactions in Moodle LMS and the social, teaching and cognitive presence scores were handled together to validate the log results whether they reflect CoI components. The Euclidian Distance Model indicates that the social presence is in a separate group with student-teacher and student-student interactions. Cognitive presence is in a group with student-system interactions and teaching presence can be evaluated in a separate group with student-content interactions. To reveal the relationship between student-student, student-teacher, student-content, student-system interactions and social, cognitive, teaching presences, the students were separated into groups according to their interaction types and presence scores (high or low). It was found out that the students with high and low cognitive presence scores had significant differences in student-content interaction. It was seen that when students' presence scores were high and low, teaching presence scores were in parallel with high or low student-system interaction scores. On the other hand, it was determined that social presence scores were in the group with both student-student and student-teacher interaction scores based on high and low scores. Furthermore, when the positions of the presences were examined concerning each other, it was seen that social and teaching presences were differentiated from cognitive presence. It can be interpreted that the student-content interaction, which is thought to be related to cognitive presence, is more prominent than other interactions. In cases where social presence was low, one of the reasons why both student-student and student-teacher interaction scores were low was understood from some participant views on the CoI scale items: "I16: Online or web-based communication is an excellent environment for social interaction. I17: I felt very comfortable talking through online environments. I19: I felt comfortable in interacting with the other students of the course." It is understood that students who do not see online environments as a suitable environment for social interaction and do not feel 
comfortable in these environments, do not use the communication tools on LMS actively and effectively, thus, resulting in low student-student and student-teacher interactions. Surely, this may be due to course design and teaching methods, and not a generalization of use to anyone. However, such evaluation may provide hints for extracting presences in relation to interactions. Considering the various definitions of social presence such as "individual's feeling himself socially in the environment", "feeling other participants in the communication process", "ability of participants to perceive other participants in the environment as real individuals", "perception of being with other people in e-learning environments" (Biocca, Harms ve Burgoon, 2003; Kreijns, 2004; Leh, 2001; Whiteman, 2002), it is foreseen that social presence can be defined by student-student interaction on LMS system. It was realized that not only the student-student interaction but also the student-teacher interaction was related to social presence and it was in the same group in the two-dimensional graph of the Euclidean distance model. At this point, the instructors' role in the instructional process and his contribution to students' participation plays a crucial role. In general, the instructor's role in directing students to participate actively in the process in all parts of the activity is considered as a part of teaching presence (Arbaugh, 2007; Garrison \& Cleveland-Innes, 2005). However, when considered within the relationships between interactions and perceptions, the findings of this study indicated that the efforts of the instructor in the process could shape the social communication of the students with each other. Cognitive presence defines the stages in the learning that takes place with knowledge construction and problem-solving (Garrison et al., 1999; Kanuka \& Garrison, 2004). Garrison et al. (2001) describe cognitive presence as the ability of online students to construct and verify meaning based on communication and thought. In this study, the student-system interaction and cognitive presence scores were found in the same group. One can infer that if an LMS interface provides more interaction with the student, this can somewhat support the benefit of the student through learning. Similar to this study, Hind et al. (2018) propose an automatic system to assess learners' cognitive presence regarding their social participation within an asynchronous online discussion. They aimed to advise instructors to be aware of learners' critical thinking and cognitive behavior to take necessary measures for efficient learning. As they tried to assess the level of students' cognitive presence according to their participation in an asynchronous online discussion, this study also suggested to assess all $\mathrm{CoI}$ components (social, teaching, cognitive presences) according to their interactions in the LMS. While assessing the social presence, the

Fig. 6 Interactions and $\mathrm{CoI}$ components relationships

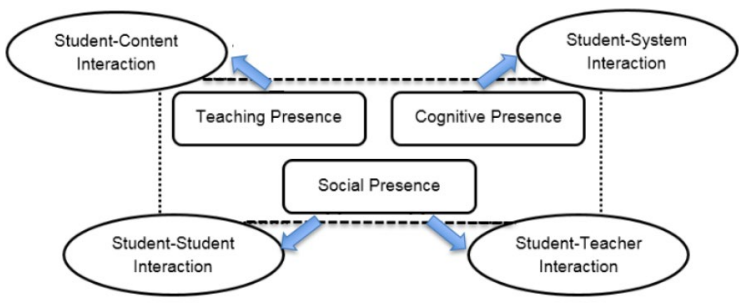


discussions and also other interactions based on the rates of online interactions in Moodle components within expert opinions were taken into consideration.

In this context, the framework for the interaction-presences relationships presented in the study can be summarized as in Fig. 6 below.

Figure 6 shows that all $\mathrm{CoI}$ components and the interaction scores were grouped in a meaningful way. However, there were differences between the presence and interaction scores of only a few participants. In particular, despite the high rates of the CoI scale, a few students had low interaction scores due to not being active enough on the system. The fact that student-content interaction was more highly related to teaching presence and that student-system interaction was more highly related to cognitive presence may only reflect a more traditional course design, not a generalization. While not all courses need to be designed in this way, our study is limited to individuals and their interactions within an LMS only. Thus, the size of the study subjects may limit the generalization of the study findings, and the statistical results. For generalization, future studies to investigate similar construct with a broader population is recommended. However, the limited number of students also played a positive role in interpreting the reasons of the students' interactions. This study differs from the others in terms of evaluating the measurements obtained through LA may be used instead of measurement tools or as supportive of measurement tools. In addition, obtaining the quantitative data from Moodle components (e.g. exam, scorm and forum) and the coefficients obtained from the Expert Evaluation Form to calculate the scores of interaction, is thought to contribute to determining the relationship between various educational situations, several variables and the interaction types. Garrison et al. (2001) expressed that communication and interaction are critical components to define presences. Undoubtedlythe presences are within the other In this study, to link presences with interactions, the presences as CoI constructs were assesed solely. This does not mean that the CoI constructs are isolated, but this might be understood as they are somewhat relatedwith some of the same Moodle components.

\section{Conclusions}

In this study, it is aimed to determine the traces of students' interactions in the online learning environment and the development of the CoI. The results suggested that in the Moodle LMS, the forum and chat areas that are used for messaging and sharing are mostly related to student-student and student-teacher interactions. Modules such as assignment and Scorm have high potential to provide student-content interactions. In addition, the use of survey, dictionary and the modules related to the system was found to constitute an interaction within the framework of student-system interaction. The results showed that student-student, student-teacher, student-content, student-system interactions, which are the basic interactions in LMSs, can be used to define and explain the CoI components to a large extent. At this point, the measurement of CoI components can be organized to provide support to instructors by showing measurements on dashboards during the process of online courses. Therefore, it is possible to achieve the expected learning outcomes by organizing the possible interactions between student-system-instructor components in a balanced way. With 
both findings and limitations that provide potential avenues for future CoI research, this study brings us one step closer to proposing a way to measure various variables in online learning through interactions and behaviors rather than learners' perceptions. Due to the COVID-19 pandemic that we have been facing since 2019, it will be possible to pave the way for instant improvements needed in online learning processes, which are becoming widespread at every education level worldwide. In this study, it was found that quantitative data related to the students' interactions can be employed to obtain objective results, especially for studies using relational methods. The study also has some certain limitations. First, this study was a small-scale study; a further study is recommended with a larger group to provide different analysis techniques for additional evidence. In addition, in this study, scoring for three types of interactions was calculated through expert evaluations. These scores can be determined by some artificial intelligence techniques. It's hoped that the suggested model can lead to the advent of learning analytics that can be used to examine log data to pull out meaningful insights and data-driven measurements from online learning settings. Further research in the form of a long study may be useful in confirming the results of this study. This study contributes to the online learning field in two folds. One offers methods to determine how learners interact in the LMSs in knowledge construction process. The other drives the development of new instructional approaches that can enhance educational uses of learning analytics not only defining the behaviors of participants but also using this data for measuring the CoI constructs as well. Consequently, the study can be considered as an example of how learning analytics gathered in various ways, in this case, through the use of Moodle data on student interactions with its components along with survey data, can help indicate whether sufficient interaction is occurring in an online course. Future studies may focus on finding ways in which the interaction types work together to achieve the CoI components.

\section{Declarations}

Conflicts of Interest None

\section{References}

Agudo-Peregrina, Á. F., Iglesias-Pradas, S., Conde-González, M., \& Hernández-García, Á. (2014). Can we predict success from log data in VLEs? Classification of interactions for learning analytics and their relation with performance in VLE-supported F2F and online learning. Computers in Human Behavior, 31, 542-550

Akyol, Z., Arbaugh, J. B., Cleveland-Innes, M., Garrison, D. R., Ice, P., Richardson, J. C., \& Swan, K. (2009). A response to the review of the community of inquiry framework. Journal of Distance Education, 23(2), 123-135

Akyol, Z., \& Garrison, D. R. (2008). The development of a community of inquiry over time in an online course: Understanding the progression and integration of social, cognitive and teaching presence. Journal of Asynchronous Learning Networks, 12, 3-22

Akyol, Z., \& Garrison, D. R. (2011). Understanding cognitive presence in an online and blended community of inquiry: Assessing outcomes and processes for deep approaches to learning. British Journal of Educational Technology, 42(2), 233-250 
Alaulamie, L. A. (2014). Teaching presence, social presence, and cognitive presence as predictors of students 'satisfaction in an online program at a Saudi University (Doctoral dissertation, Ohio University)

Anderson, T., Rourke, L., Garrison, D. R., \& Archer, W. (2001). Assessing teaching presence in a computer conferencing context. Journal of Asynchronous Learning Networks, 5(2), 1-17

Anowar, F., Sadaoui, S., \& Selim, B. (2021). Conceptual and empirical comparison of dimensionality reduction algorithms (PCA, KPCA, LDA, MDS, SVD, LLE, ISOMAP, LE, ICA, t-SNE). Computer Science Review, 40, 100378

Arbaugh, J. B. (2007). An empirical verification of the community of inquiry framework. Journal of Asynchronous Learning Networks, 11(1), 73-85

Arbaugh, J. B., \& Benbunan-Fich, R. (2007). The importance of participant interaction in online environments. Decision Support Systems, 43(3), 853-865

Arbaugh, J. B., Cleveland-Innes, M., Diaz, S. R., Garrison, D. R., Ice, P., Richardson, J. C., \& Swan, K. P. (2008). Developing a community of inquiry instrument: Testing a measure of the community of inquiry framework using a multi-institutional sample. The Internet and Higher Education, 11(3-4), $133-136$

Arbaugh, J. B., \& Hwang, A. (2006). Does "teaching presence" exist in online MBA courses? The Internet and Higher Education, 9(1), 9-21

Beldarrain, Y. (2006). Distance education trends: Integrating new technologies to foster student interaction and collaboration. Distance education, 27(2), 139-153

Bernard, R. M., Abrami, P. C., Borokhovski, E., Wade, C. A., Tamim, R. M., Surkes, M. A., \& Bethel, E. C. (2009). A meta-analysis of three types of interaction treatments in distance education. Review of Educational Research, 79(3), 1243-1289

Biocca, F., Harms, C., \& Burgoon, J. K. (2003). Toward a more robust theory and measure of social presence: Review and suggested criteria. Presence: Teleoperators \& Virtual Environments, 12(5), 456-480

Borg, I., Groenen, P. J., \& Mair, P. (2012). Applied multidimensional scaling. Springer Science \& Business Media

Boston, W., Díaz, S. R., Gibson, A. M., Ice, P., Richardson, J., \& Swan, K. (2009). An exploration of the relationship between indicators of the community of inquiry framework and retention in online programs

Castellanos-Reyes, D. (2020). 20 Years of the Community of Inquiry Framework.TechTrends: Linking Research \& Practice to Improve Learning, 64(4)

Clausen, S. E. (1998). Applied correspondence analysis: An introduction (121 vol.). Sage

Cox, M., \& Cox, T. (2008). Multidimensional Scaling. Handbook of Data Visualization. Berlin, Heidelberg: Springer Handbooks Comp.Statistics. Springer

Creswell, J. W., \& Poth, C. N. (2016). Qualitative inquiry and research design: Choosing among five approaches. Sage publications

Çakıroğlu, Ü., \& Kılıç, S. (2018). Understanding community in synchronous online learning: do perceptions match behaviours? Open Learning: The Journal of Open, Distance and e-Learning, 1-17

Darabi, A., Arrastia, M. C., Nelson, D. W., Cornille, T., \& Liang, X. (2011). Cognitive presence in asynchronous online learning: A comparison of four discussion strategies. Journal of Computer Assisted Learning, 27(3), 216-227

Eom, S. B., Wen, H. J., \& Ashill, N. (2006). The determinants of students' perceived learning outcomes and satisfaction in university online education: An empirical investigation. Decision Sciences Journal of Innovative Education, 4(2), 215-235

Etikan, I., Musa, S. A., \& Alkassim, R. S. (2016). Comparison of convenience sampling and purposive sampling. American Journal of Theoretical and Applied Statistics, 5(1), 1-4

Ferguson, R. (2012). Learning analytics: drivers, developments and challenges. International Journal of Technology Enhanced Learning, 4(5/6), 304-317

Garrison, D. R., Anderson, T., \& Archer, W. (1999). Critical inquiry in a text-based environment: Computer conferencing in higher education. The Internet and Higher Education, 2(2-3), 87-105

Garrison, D. R., Anderson, T., \& Archer, W. (2001). Critical thinking, cognitive presence, and computer conferencing in distance education. American Journal of Distance Education, 15(1), 7-23

Garrison, D. R., Anderson, T., \& Archer, W. (2010). The first decade of the community of inquiry framework: A retrospective. The Internet and Higher Education, 13(1-2), 5-9

Garrison, D. R., \& Arbaugh, J. B. (2007). Researching the community of inquiry framework: Review, issues, and future directions. The Internet and Higher Education, 10(3), 157-172 
Garrison, D. R., \& Cleveland-Innes, M. (2005). Facilitating cognitive presence in online learning: Interaction is not enough. The American Journal of Distance Education, 19(3), 133-148

Given, L. M. (Ed.). (2008). The Sage encyclopedia of qualitative research methods. Sage publications

Greenacre, M. (2007). Correspondence analysis in practice (2nd ed.). Boca Raton, FL: Chapman \& Hall

Hillman, D. C., Willis, D. J., \& Gunawardena, C. N. (1994). Learner-interface interaction in distance education: An extension of contemporary models and strategies for practitioners. American Journal of Distance Education, 8(2), 30-42

Hind, H., Idrissi, M. K., \& Bennani, S. (2018, April). Automatic Assessment of CoI-Cognitive Presence within Asynchronous Online Learning. In 2018 17th International Conference on Information Technology Based Higher Education and Training (ITHET) (pp. 1-5). IEEE

Jan, S. K., \& Vlachopoulos, P. (2019). Social network analysis: A framework for identifying communities in higher education online learning. Technology, Knowledge and Learning, 24(4), 621-639

Jansson, M., Hrastinski, S., Stenbom, S., \& Enoksson, F. (2021). Online question and answer sessions: How students support their own and other students' processes of inquiry in a text-based learning environment. The Internet and Higher Education, 51, 100817

Kanuka, H., \& Garrison, D. R. (2004). Cognitive presence in online learning. Journal of Computing in Higher Education, 15(2), 21

Kovanović, V., Joksimović, S., Waters, Z., Gašević, D., Kitto, K., Hatala, M., \& Siemens, G. (2016, April). Towards automated content analysis of discussion transcripts: A cognitive presence case. In Proceedings of the sixth international conference on learning analytics \& knowledge (pp. 15-24). ACM

Kovanović, V., Gašević, D., Joksimović, S., Hatala, M., \& Adesope, O. (2015). Analytics of communities of inquiry: Effects of learning technology use on cognitive presence in asynchronous online discussions. The Internet and Higher Education, 27, 74-89

Kovanović, V., Joksimović, S., Poquet, O., Hennis, T., de Vries, P., Hatala, M., \& Gašević, D. (2019). Examining communities of inquiry in Massive Open Online Courses: The role of study strategies. The Internet and Higher Education, 40, 20-43

Kozan, K., \& Richardson, J. C. (2014). Interrelationships between and among social, teaching, and cognitive presence. The Internet and Higher Education, 21, 68-73

Kramer, A. D., Oh, L. M., \& Fussell, S. R. (2006). Using linguistic features to measure presence in computer-mediated communication. In Proceedings of the SIGCHI conference on Human Factors in Computing Systems (pp. 913-916). ACM

Kreijns, K. (2004). Sociable CSCL environments: Social Affordances. Sociability, and Social Presence

Leh, A. S. (2001). Computer-mediated communication and social presence in a distance learning environment. International Journal of Educational Telecommunications, 7(2), 109-128

Lowenthal, P. R. (2012). Social presence: What is it? How do we measure it?. University of Colorado at Denver

Lowenthal, P. R., \& Dunlap, J. C. (2014). Problems measuring social presence in a community of inquiry. E-Learning and Digital Media, 11(1), 19-30

Lowenthal, P. R., \& Leech, N. L. (2010). Mixed research and online learning: Strategies for improvement. Online education and adult learning: New frontiers for teaching practices (pp. 202-211). IGI Global

Maddrell, J. A., Morrison, G. R., \& Watson, G. S. (2011). Community of inquiry framework and learner achievement. In Annual Meeting of the Association of Educational Communication \& Technology, Jacksonville, FL. Retrieved fromhttp://www.jennifermaddrell.com/wp-content/uploads/2011/11/ MADDRELL-MORRISONWATSON-AECT-Featured-Research-Paper-FINAL-20111110.pdf

Mills, J. J. (2016). A Mixed Methods Approach To Investigating Cognitive Load And Cognitive Presence In An Online And Face-To-Face College Algebra Course. Theses and Dissertations--Education Science. 8. Retrieved fromhttps://uknowledge.uky.edu/edsc_etds/8

Morueta, R. T., López, P. M., Gómez, Á. H., \& Harris, V. W. (2016). Exploring social and cognitive presences in communities of inquiry to perform higher cognitive tasks. The Internet and Higher Education, 31, 122-131

Nieuwoudt, J. (2018). Exploring online interaction and online learner participation in an online science subject through the lens of the interaction equivalence theorem. Student Success, 9(4), 53-62

Öztürk, E. (2012). An Adaptation of the Community of Inquiry Index: The Study of Validity and Reliability. Elementary Education Online, 11(2), 408-422

Rahi, S. (2017). Research design and methods: A systematic review of research paradigms, sampling issues and instruments development. International Journal of Economics \& Management Sciences, $6(2), 1-5$ 
Rubin, B., Fernandes, R., \& Avgerinou, M. D. (2013). The effects of technology on the Community of Inquiry and satisfaction with online courses. The Internet and Higher Education, 17, 48-57

Shea, P., \& Bidjerano, T. (2009). Cognitive presence and online learner engagement: A cluster analysis of the community of inquiry framework. Journal of Computing in Higher Education, 21(3), 199

Shea, P., \& Bidjerano, T. (2010). Learning presence: Towards a theory of self-efficacy, self-regulation, and the development of a communities of inquiry in online and blended learning environments. Computers \& Education, 55(4), 1721-1731

Shea, P., \& Bidjerano, T. (2012). Learning presence as a moderator in the community of inquiry model. Computers \& Education, 59(2), 316-326

Shea, P., Hayes, S., \& Vickers, J. (2010). Online instructional effort measured through the lens of teaching presence in the community of inquiry framework: A re-examination of measures and approach. The International Review of Research in Open and Distributed Learning, 11(3), 127-154

Shea, P. J., Pickett, A. M., \& Pelz, W. E. (2003). A follow-up investigation of "teaching presence" in the SUNY Learning Network. Journal of Asynchronous Learning Networks, 7(2), 61-80

Siemens, G., \& d Baker, R. S. (2012). Learning analytics and educational data mining: towards communication and collaboration. In Proceedings of the 2 nd international conference on learning analytics and knowledge (pp. 252-254). ACM

So, H. J., \& Brush, T. A. (2008). Student perceptions of collaborative learning, social presence and satisfaction in a blended learning environment: Relationships and critical factors. Computers \& education, 51(1), 318-336

Stein, D. S., Wanstreet, C. E., Glazer, H. R., Engle, C. L., Harris, R. A., Johnston, S. M. ... Trinko, L. A. (2007). Creating shared understanding through chats in a community of inquiry. The Internet and Higher Education, 10(2), 103-115

Stenbom, S. (2018). A systematic review of the Community of Inquiry survey. The Internet and Higher Education, 39, 22-32

Tirado, R., Hernando, Á., \& Aguaded, J. I. (2015). The effect of centralization and cohesion on the social construction of knowledge in discussion forums. Interactive Learning Environments, 23(3), 293-316

Vivakaran, M. V., \& Maraimalai, N. (2018). Networked Learning and Learning Analytics: A Study on the Employment of Facebook in a Virtual Training Program.Interactive Learning Environments, 1-14

Xing, W., Guo, R., Petakovic, E., \& Goggins, S. (2015). Participation-based student final performance prediction model through interpretable Genetic Programming: Integrating learning analytics, educational data mining and theory. Computers in Human Behavior, 47, 168-181

Wanstreet, C. E., \& Stein, D. S. (2011). Presence over time in synchronous communities of inquiry. American Journal of Distance Education, 25(3), 162-177

Wertz, R. E. (2022). Learning presence within the Community of Inquiry framework: An alternative measurement survey for a four-factor model. The Internet and Higher Education, 52, 100832

Whiteman, J. A. M. (2002). Interpersonal communication in computer mediated learning. Retrieved from http://eric.ed.gov/PDFS/ED465997.pdf

Wicks, D. A., Craft, B. B., Mason, G. N., Gritter, K., \& Bolding, K. (2015). An investigation into the community of inquiry of blended classrooms by a Faculty Learning Community. The Internet and Higher Education, 25, 53-62

Publisher's Note Springer Nature remains neutral with regard to jurisdictional claims in published maps and institutional affiliations. 